\title{
Entre interesses e possibilidades: a aproximação da política bragantina ao Rio da Prata
}

\author{
Between interests and opportunities: \\ The Bragantina's policy approach to the Rio da Prata
}

Ronaldo Bernardino Colvero*

\begin{abstract}
Resumo: Em 1808, interesses antigos, aliados às novas possibilidades começaram a ser analisados para que Portugal garantisse, além de sua hegemonia na América, medidas econômicas renovadas para tentar resolver velhos problemas. O objetivo deste artigo é compreender a forma com que a Coroa portuguesa, por meio da especulação diplomática disponível à época, movimentou seu recém instalado aparato político, econômico e militar na colônia do Brasil no intuito de expandir suas imprecisas fronteiras meridionais até a região do Rio da Prata logo da chegada da Corte portuguesa em território americano.
\end{abstract}

Palavras-chaves: Rio da Prata, Política,Diplomacia

\begin{abstract}
In $1808^{\text {th }}$, old interests coupled with new opportunities began to be examined to guarantee that Portugal, in addition to its hegemony in America, renewed economy measures to try solved old problems. The aim of this article is to understand the form that the Portuguese Crown, through the diplomatic speculation available at the time, moved its newly installed apparatus political, economic and military power in the colony of Brazil, with the objective to expand your imprecise southern borders to the Rio da Prata region once the arrival of the Portuguese Court in American territory.
\end{abstract}

Keywords: Rio da Prata, Politics, Diplomacy

* Professor titular da Universidade Federal do Pampa, campus de São Borja. Diretor do curso de Ciências Sociais - Ciência Política. Doutor em História das Sociedades ibéricas e americanas pelo PPGH da PUCRS. E-mail: <ronaldo.colvero@unipampa.edu.br>. 


\section{Introdução}

Alguns pesquisadores propõem que o projeto de mudar a sede e a estrutura do governo português para a colônia já existia mesmo antes da vinda da família real ao Brasil em 1808. Esse projeto também já contava com o apoio inglês, mas foi a invasão de Portugal por tropas francesas sob o comando de Napoleão, representado pelo general Junot, que acelerou os planos da mudança. Esse fato teria importância capital para, mais tarde, serem deflagrados os processos de abertura econômica da colônia e da independência do Brasil. De acordo com Sheila de Castro Faria (2001, p. 107):

independente das intenções iniciais, o fato mostrou-se relevante para o entendimento do processo de independência e, mais ainda, para as transformações que marcaram a sociedade brasileira, em níveis culturais, políticos e econômicos. Pela primeira vez na história, um Rei colocou os pés em sua colônia.

Em 29 de novembro de 1807, as embarcações ocupadas pela família real e toda a "camarilha" que se beneficiava da máquina governamental, mais criados, toda a receita que fora possível carregar, obras das mais variadas, uma tipografia e tudo mais que era necessário ao translado da corte saíram de Portugal em direção ao Brasil. Entretanto, aqui, o vice-rei dom Marcos de Noronha e Britto desconhecia completamente o fato da viagem, somente tomando ciência disso em janeiro de 1808, quando toda a família já estava prestes a aportar em terras coloniais e, mais precisamente, no Rio de Janeiro.

O vice-rei, então, tomou medidas de urgentíssima efetividade, incluindo o despejo sumário de diversas famílias que residiam em prédios próximos à sede do governo e de parte do palácio em que ele próprio residia. Além das medidas adotadas na cidade, foram expedidas correspondências às autoridades e aos governadores de Minas Gerais e São Paulo, para que providenciassem o envio de todos os víveres que pudessem conseguir à sede do governo. Entretanto, o príncipe regente, em virtude da separação das naus durante uma tempestade, aportou primeiramente em Salvador, demorando mais de trinta dias para então dirigir-se à capital (Norton, 1979). ${ }^{1}$

É possível se ter uma idéia da chegada da família real com detalhes pormenorizados e em tom romanesco, através dessa bela narrativa de Norton que pode servir de base para verificar, de maneira sucinta, as alterações políticas, econômicas, administrativas e culturais no Brasil após a chegada da família real. 
As medidas adotadas por dom João logo de sua chegada ao Brasil, em 1808, principalmente a de abolir as restrições comerciais da colônia abrindo seus portos, possibilitaram a ampla liberdade de comercialização com outros países" 2 . Esse fato "é considerado por muitos analistas o verdadeiro fim do período colonial brasileiro, já que teria rompido a premissa básica do sistema: a de que a colônia só poderia comercializar com sua Metrópole" (FARIA, 2001, p. 107). Segundo Oliveira Lima,

a abertura dos portos nacionais constitui em verdade uma medida altamente simpática e liberal, mas não se pode dizer que representasse uma desinteressada e intencional cortesia do príncipe regente aos seus súditos ultramarinos. Era antes uma precaução econômica necessária e inadiável. (Lima, 1996, p. 136)

Os comerciantes portugueses da Metrópole ficaram bastante desgostosos com as medidas adotas por dom João. Mesmo que as tarifas fossem mais baixas para estes que para os comerciantes de outras nacionalidades, a questão era que a abertura comercial da colônia para outras nações tirava uma grande fatia do mercado exportador de Portugal. É simples de ser entendida a indignação dos portugueses, apoiando-se estritamente no plano econômico, pois, antes da abertura dos portos, eles tinham todas as vantagens em comercializar com a colônia brasileira, visto que era a própria colônia que arcava com todas as despesas, já que:

os impostos diretos pagos pelo comércio brasileiro, ou melhor, o comércio estabelecido no Brasil, e que indiretamente recaíam sobre os consumidores nacionais, como não podia deixar de acontecer pela falta de concorrentes nas transações coloniais, subiam a 150\% no cálculo feito por Luccock, que foi negociante da praça do Rio depois da franquia dos portos. Quer isto simplesmente dizer que Portugal recebia 250 libras por cada 100 libras mandadas sob forma de material de escambo ou antes de venda e de trabalho, além dos ganhos apurados nos fretes, juros do capital empregado, monopólios e estancos etc." (Lima, 2001, p. 240)

Podemos, no entanto, perceber que esse comércio, mesmo após a abertura dos portos, continuou sendo muito lucrativo para Portugal,

2 É importante frisar que os países dos quais trata a Lei responsável pela abertura dos portos do Brasil são somente aqueles que colaboravam com a corte portuguesa, principalmente, naquela ocasião, a Inglaterra. 
que acumulava altíssimos valores provenientes das importações e exportações. Isso foi possível porque o Brasil produzia exclusivamente para exportar e devia vender para poder comprar o que não era produzido na colônia. Essa situação dava a Portugal a possibilidade de cobrar o que lhe fosse conveniente, ou seja, explorar a colônia ao máximo e enquanto fosse possível.

A abertura dos portos possibilitou o aumento do comércio legal por toda a costa do Brasil, de norte a sul, chegando até Montevidéu e, mais tarde, até os rios Paraná e Uruguai. Isso levou a que a colônia brasileira se tornasse um grande baluarte do comércio na América do Sul, conseguindo crescer por meio do comércio local, que se dava inicialmente pela costa, desenvolvendo cidades, povoados, vilas, tanto no litoral do oceano Atlântico quanto nas margens dos rios e afluentes, proporcionando a distribuição de produtos dentro do continente.

As relações comerciais entre as cidades ribeirinhas e litorâneas brasileiras foram consolidadas pela abertura dos portos, mas isso não significa que tais relações não existissem antes da decisão real. O que corriqueiramente acontecia era o contrabando, prática comum, que fora determinante para o crescimento econômico do Brasil nos primeiros dois séculos de colonização e que continuou sendo amplamente realizado de norte a sul do país. Na porção meridional, o contrabando colaborou especialmente para os contatos entre luso-brasileiros e hispanoplatinos. Este problema, aos olhos do governo, era motivo de constante discussão entre os representantes das Coroas portuguesa e espanhola, pois constituía-se num problema à arrecadação de tributos para o Estado, além de ser um entrave à formalização dos limites territoriais na América Meridional.

Portanto, o objetivo deste artigo é verificar as nuanças pelas quais se torna possível compreender a forma com que a Coroa portuguesa movimentou seu recém instalado aparato político, econômico e militar na colônia do Brasil, em 1808, no intuito de expandir suas imprecisas fronteiras meridionais até a região do Rio da Prata.

\section{As impressões a partir da chegada da Corte em solo brasileiro}

Mesmo com a chegada da corte, a liberação dos portos para comercialização com outras nações e o crescimento da administração local, intensificando os serviços burocráticos que se faziam necessários à administração da colônia, não houve mudança na posição da elite 
econômica existente. $\mathrm{O}$ que se alterou foi a ampliação do volume de negociações entre a colônia - agora com novas perspectivas de crescimento - e outros países de todas as partes do mundo. Assim, podemos verificar que a estrutura anterior não mudou; apenas se ampliou de forma considerável. (Fragoso in: Fragoso, et. al., 2001)

Com essa liberdade de comercialização, o Brasil iniciava uma nova fase, um período de crescimento econômico voltado ao mercado internacional. Isso durou até o início do ano de 1816, quando a elevação do Brasil a Reino Unido, nas mesmas condições de Portugal e Algarves, possibilitou que os comerciantes disponibilizassem à população variados produtos vindos de outros países, posto que também puderam lucrar mais. Assim, é possível dizer que o Brasil obteve certa autonomia administrativa local, que resultou, posteriormente, na autonomia política.

Como resultado das medidas burocráticas iniciadas com o estabelecimento da corte portuguesa no Brasil foi constituído o novo ministério, porém com peças já antigas no cenário português: o Ministério dos Negócios do Reino foi composto por dom Fernando José de Portugal e Castro, $2^{\circ}$ marquês de Aguiar; o ministério dos Negócios Estrangeiros e da Guerra passou a ser comandado por dom Rodrigo de Sousa Coutinho ${ }^{3}$, futuro conde de Linhares; por último, o ministério dos Negócios da Marinha e do Ultramar que foi chefiado por João Rodrigues de Sá e Melo, o visconde de Anadia.

Nessa nova formação ministerial destacamos a personalidade e as realizações do conde de Linhares perante o governo de dom João. A política implementada por dom Rodrigo foi considerada uma continuidade dos desejos e das políticas do marquês de Pombal, como pode ser verificado quando vemos algumas medidas protecionistas e a adesão à liberdade econômica demonstradas por este ministro, sem contar sua formação prática e inclinação ideológica voltadas ao modelo pombalino e anglófilo ${ }^{4}$. Norton, corroborando com essa visão, garante

\footnotetext{
Seu nome completo era Rodrigo Domingos Antônio de Sousa Coutinho, que recebera o título de conde de Linhares. Nasceu em 1745, em Portugal, e faleceu em 1812, no Brasil. Foi por duas vezes ministros da pasta de Estrangeiros e da Guerra, tendo assumido em 1801 e em 1808. Vários foram os escritores que sobre ele dissertaram ou escreveram algumas linhas, em função de sua preponderância nas decisões que eram emitidas pela regência do príncipe dom João durante o período de 1808 a 1812. A princesa Carlota, por sua vez, sempre o detestara, chamando-os, dentre outras coisas, de "Torvelinho", ou seja, que vivia em constante agitação.

4 Tanto o marquês de Pombal quanto o conde de Linhares partilhavam de uma forte admiração e simpatia pelos ingleses.
} 
que o conde de Linhares chegou a ser chamado, sem falsa ironia, de "o Novo Pombal" (NORTON, 1979, p. 32).

Como exemplo das idéias que defendia em relação à administração, podemos ver as anotações escritas antes da partida para a América, nas quais já idealizava a constituição de um Estado nos moldes absolutistas. A colônia americana, dizia dom Rodrigo:

A feliz posição do Brasil [...] dá aos seus possuidores uma tal superioridade de forças pelo aumento de povoação, que se alimenta dos seus produtos, e facilidade do comércio, que, sem grandes erros políticos jamais os vizinhos do norte e do sul lhes poderão ser fatais, e pelo mar só pelo comércio interlopo e fraudulento é que necessariamente devem inquietar-nos logo que a nossa taxação se afastar dos princípios que unicamente podem suspender e contrariar este cruel flagelo. Para segurar os meios da nossa superior força, é que com olhos políticos se deve estabelecer a divisão das nossas capitanias, e aí salta aos olhos a necessidade que há de formar dois grandes centros de força, um ao norte, e o outro ao sul, debaixo dos quais se reúnam os territórios, que a natureza dividiu tão providamente por grandes rios, ao ponto de fazer ver que esta concepção política é ainda mais natural do que artificial. Os dois grandes centros são, sem contradição o Pará e o Rio de Janeiro ${ }^{5}$

Sua máxima política era "Agir. Chorar em lugar de obrar quando o perigo é manifesto, é prova d'imbecilidade" " Dessa forma, acreditava ser a melhor arma "reformar de cima, transformar sem substituir, melhorar sem revolucionar" (Lima, 1996, p. 140), tanto para manter intacta a empresa absolutista quanto para prover o desejado progresso. Dom Rodrigo de Sousa Coutinho faleceu por causas não suficientemente elucidadas, em 1812, aos 56 anos de idade, deixando um legado bastante considerável para administrações futuras, principalmente novos hábitos na corte e estreitas relações comerciais e políticas com representantes estrangeiros.

5 Exposição transcrita na obra do marquês de Funchal "O conde Linhares", p. 44 et seq. apud Norton, 1979, p. 33. Cabe observar que as transcrições das fontes utilizadas neste artigo obedecerão a grafia original das mesmas.

6 Trecho de carta enviada a D. Fernando Portugal, no ano de 1809, em função das reclamações advindas do Reino (apud Lima, 1996, p. 139). A menção ao Pará, como um dos grandes centros, devia-se em razão de ter sido aquele, durante quase dois séculos, um Estado administrativamente independente do Estado do Brasil Em 1772, por obra das reformas pombalinas, foi dividido em Estado do Grão-Pará e do Rio Negro, com capital em Belém, e o Estado do Maranhão e Piauí, cuja capital era São Luís. Ambos mantinham relações diretas com Lisboa até a chegada da família real ao Brasil, em 1808. A anexação ao Estado brasileiro de fato só ocorreu após a independência, em 1822, quando passou a ser a Província do Grão-Pará. 
Durante todo o período em que esteve à frente dos negócios exteriores do Império, nunca deixou de tentar, se não anular, ao menos controlar muito de perto as intenções da esposa do príncipe regente, dona Carlota Joaquina. Os embates entre ambos girariam principalmente em torno da questão platina, a partir de 1808, sobre a qual Carlota mantinha o foco de seus desejos e dom Rodrigo, por sua vez, também tentava impor, com a devida anuência de dom João, a sua visão colonialista, expansionista e de controle econômico.

Podemos afirmar que as investidas do príncipe regente, alimentadas pelas assertivas do conde de Linhares, caracterizaram uma nova etapa das relações mantidas entre a Coroa portuguesa e os vice-reinados espanhóis na América. As correspondências trocadas desde o início de 1808 foram a "ponta do iceberg" que se pronunciava sobre o Vice-Reinado do Rio da Prata. A partir desse momento, e apesar de alguns reveses, Portugal se lançaria decididamente à conquista de novos territórios na América Meridional.

Destarte, à medida que a situação na região ibérica se agravava, o governo português estabelecido no Brasil dava início a um projeto de Estado que visava, ao menos como justificativa, manter a solidez da América colonial por meio de uma possível união ibero-americana, regida pela Coroa de Portugal. Para isso, suscitou alguns motivos que, a priori, não surtiram o efeito desejado na camada dirigente do ViceReinado do Rio da Prata.

Praticamente em todo o vice-reinado, antes mesmo do recebimento das correspondências enviadas pelas principais autoridades do governo português, já estava sendo posta em prática uma reorganização de tropas para evitar a possível invasão que a chegada do príncipe regente português, no entendimento dos governantes platinos, anunciava. O tempo iria demonstrar que os dirigentes do vicereinado não estariam equivocados. Deu-se início, portanto, a uma mobilização defensiva no Rio da Prata, que pode ser percebida pela correspondência reservada de 17 de março de 1808, entre o vice-rei interino ${ }^{7}$ de Buenos Aires, Santiago de Liniers y Brémont ${ }^{8}$, e o ministro

7 O título de vice-rei foi confirmado em finais de 1807 , mas chegou ao conhecimento de Liniers somente em junho de 1808.

8 Liniers era francês, nascido em Niort (Poitiers), no ano de 1753. Em 1775, iniciou sua escalada militar na Marinha espanhola, a qual the possibilitou assistir à conquista da Colônia do Sacramento. Em 1788, passou ao Rio da Prata, de onde, no comando das lanchas canhoneiras de Montevidéu, combateu os ingleses que atacavam o comércio espanhol (1796-1802). Tomada a cidade de Buenos Aires pelos britânicos comandados por Beresford (1806), Liniers, nessa época chefe da estação daquele porto, reconquistou-a e fez prisioneiro o general inglês e todas as suas tropas, pelo que recebeu o título de brigadeiro 
da Guerra, dom Antonio Olaguer Feliu, na qual o primeiro pedia que:

en el caso de peligrár la Paz entre nuestra Nacion y la Portuguesa se Sirva V.E. promover que se haga un extraordinario esfuerzo para surtir esta Provincia del competente numero de Tropa Armas, Municiones y demàs efectos de Guerra correspondientes â èl, à fin de aseguràr estos interesantes Dominios [...] y evitar los incalculables quebrantos que nos ocasionaria la perdida de ellos ${ }^{9}$.

As ações levadas a cabo para proteger o vice-reinado estavam sendo arregimentadas, pois a sua extensão e a longa fronteira com o Estado português eram pontos de extrema preocupação. Por outro lado, a falta de tropas, dinheiro e armas para protegê-las preocupava os dirigentes do vice-reinado, como informava o governador do Paraguay, dom Manuel Gutierrez, ao vice-rei em 17 de março de 1808:

En el precente estado de indefencion en que me hallo, sin Dinero, sin Municiones, sin Armas, y hasta careciendo de un Maestro Armero [...] yo no puedo responder al REY de esta Provincia y mucho menos de la de Miciones comprometiendome unicamente, como me comprometo, à tomar un Fucil, y de este modo, ó de otro qualquiera, derramar la ultima gota de mi sangre, por el REY, y por la Patria, pero sin ser responsable de lo que no puedo defender, ni conservar si los Enemigos me atacan ${ }^{10}$.

De fato, as notícias enviadas por Jose Lariz, comandante de fronteira em Santo Tomé, ao governador do Paraguay, no início do mês de março, davam conta de que o perigo de um ataque era iminente. $\mathrm{Na}$

da Real Armada. A Inglaterra, inconformada com o duro golpe recebido em Buenos Aires, no final de 1806, destacou em frente a Montevidéu uma frota sob comando do Almirante Murray que conduzia 15.000 homens, conforme as ordens do general Whitelocke. As forças britânicas tomaram a praça, Liniers, que havia acudido em seu auxílio, retirou-se para Buenos Aires. Nesta cidade, rechaçou o ataque inglês, obrigando o inimigo a retirar-se e a devolver a praça de Montevidéu depois de ter causado mais de 4.000 baixas (1807). Por isso, Liniers tornou-se chefe de esquadra e foi nomeado interinamente como vice-rei, governador e capitão-general das províncias do Rio da Prata. Em Papagayos (Argentina), no ano de 1810, por determinação da Junta Revolucionária de Buenos Aires, juntamente com Gutiérrez de la Concha e outros espanhóis, foi morto a tiros. Consultar: $<$ http:// cvc.cervantes.es/actcult/museo naval/sala $7 /$ personajes/personajes $11 . \mathrm{htm}>$. Acesso em: 19/12/2005. Assim como, para ter conhecimento sobre a genealogia do vice-rei, deve-se consultar $<$ http://ar.geocities.com/genealogia_fernandez/pafg1139.htm\#32634>. Acesso em: 19/12/2005.

9 Política lusitana en el Rio de la Plata. Colección Lavradio I (1808-1809), 1961, p. 22.

${ }^{10}$ Política lusitana en el Rio de la Plata. Colección Lavradio I (1808-1809), 1961, p. 27. 
correspondência, Lariz afirmava, "que aquel Govierno [português], ha mandado reunir sus tropas; que las estan disciplinando diariamente en el manejo del Arma, y de el de cañon y que estan entricherandose, y haciendo Quarteles en la Vanda Oriental de Uruguay"11.

Assim, ainda não estavam claras aos vizinhos platinos as reais intenções dos portugueses em relação às suas fronteiras. Por conseqüência, qualquer movimento era motivo para que houvesse uma intensa troca de correspondências reservadas entre os principais setores da camada dirigente platina.

\section{Curado e a observação da realidade platina}

No dia 13 de março de 1808, para levar adiante o projeto português de expansão até o Vice-Reinado do Rio da Prata, o ministro dom Rodrigo de Sousa Coutinho, assim que chegou ao Rio de Janeiro, enviou uma correspondência ao Cabildo ${ }^{12}$ de Buenos Aires. O ministro, possivelmente, tinha em mente as indicações do comandante Joaquim Xavier Curado ${ }^{13}$, passadas anteriormente à chegada da família real

${ }_{11}$ Política lusitana en el Rio de la Plata. Colección Lavradio I (1808-1809), 1961, p. 28-29.

${ }^{12} \mathrm{O}$ Cabildo, durante o período colonial, funcionava como um conselho municipal, onde o elemento criollo deveria estar representado. Nessa instituição havia um conjunto de cargos que, freqüentemente, eram vendidos pela administração espanhola quando houvesse necessidade de dinheiro. Por isso, a função dentro do Cabildo era por vezes tratada como propriedade privada, sendo negociada e, quase sempre, hereditária. Em situações graves, era organizado um Cabildo Abierto, onde todos os moradores da cidade reuniam-se para tomar as decisões. Ao final do século XVIII, a importância desta instituição estava abalada pelo poder conferido aos vice-reis e corregedores. (Azevedo, 1990, p. 66-67) Conforme José Cláudio Williman e Carlos Pons (1977, p. 61-63), as funções do Cabildo seriam: a) legislativas, devendo redigir as "ordenanzas municipales"; b) eleitorais, tendo em vista a eleição de seus próprios membros; c) judiciais, sendo a segunda instância depois da decisão dos Alcaldes Ordinarios; d) administrativas, sendo responsáveis pelas necessidades urbanas do município.

${ }^{13}$ Segundo nota de artigo de Francisca Nogueira de Azevedo, Joaquim Xavier Curado era filho de João Gomes Curado e de dona Maria Josefa Pinheiro. Nasceu no dia 1 de março de 1743, na Freguesia de Meia Ponte, Estado de Goiás. Ficando órfão de pai, partiu de sua cidade natal com destino ao Rio de Janeiro, onde pretendia habilitar-se para ingressar na Universidade de Coimbra. Com apenas 21 anos, ingressou no exército como soldado, embarcando com seu regimento, algum tempo depois, para a fronteira sul em virtude da invasão espanhola. No relatório que o vice-rei Luiz de Vasconcelos remeteu ao conde de Rezende, é feita uma relação dos numerosos serviços prestados por Xavier Curado, sendo ele recomendado para substituí-lo no cargo de Vice-rei. Em 1797, o conde de Rezende apresentou-o a dom Rodrigo de Sousa Coutinho com as melhores referências. No último período do governo do conde de Rezende foi nomeado governador de Campos. Deixando o cargo, seguiu para a Europa no desempenho de outra função, "por demais importante", junto à corte de Lisboa. Regressou ao Rio de Janeiro em 1800. Ver: Lago, s.d., p. 83; Silva in: Azevedo, 2011. 
portuguesa ao Brasil, quando este ainda era governador de Santa Catarina. Essas notícias acerca do Rio da Prata eram resultado das incursões secretas que algumas vezes foram realizadas pelo comandante português em território platino para sondar a organização militar e política do vice-reinado.

Na missiva, o ministro português tentava convencer os cabildantes de Buenos Aires que os fatos ocorridos na Europa também levado à "total sujecion de la Monarquia Española en Europa a la Francia, y la casi entera aniquilasion de la misma por los perfidos consejos del maior enemigo [...] donde resulta el total abandono de los Pueblos Españoles que abitan la America"14. Dessa forma, após descrever a situação da Metrópole diante da invasão de Napoleão e, na tentativa de sensibilizar os governantes do Prata, dom Rodrigo revelava sutilmente o que podia ser um dos pontos-chaves para se compreenderem os motivos que impulsionavam o projeto de "proteção": o comércio. Em suas palavras, a população do vice-reinado

se hallan de nuevo grabados con nuebos y excesibos impuestos, despues de tantos servicios practicados en la ultima ebacuasion de los Ingleses, y Reconquista de la Ciudad de Buenos Ayres, y conosiendo Su Altesa Real [...] no podia dejar de ser agradable a Ustd y de traerle a la memoria que por su medio podria evitar la ruina de su Comerico, y las fatales catastrofes a que se halla espuesto el Rio de la Plata ${ }^{15}$.

Notamos, pelo comentário exposto, o quanto os interesses comerciais eram essenciais para a manutenção do vice-reinado, apesar de não se ter a precisa idéia de qual tipo de comércio lhe aprazia mais: se o livrecambista ou o monopolista. Sabendo desse ponto nevrálgico e, também, muito interessado na participação que poderia alcançar em dito comércio com Buenos Aires, dom João, através de dom Rodrigo, decidiu "ofrecerle tomar al Cavildo y Pueblo de la Ciudad de Buenos Ayres y todo el Virrenato, vajo Su Real Proteccion", garantindo que manteria "todas sus esenciones y jurisdicciones, y empeñandole $\mathrm{Su}[. .$.$] palabra,$ no solo de no grabarlos com nuebos impuestos, sino aun de asegurarle $\mathrm{Su}$ Comercio libre è integro" 16 .

\footnotetext{
${ }_{14}$ Política lusitana en el Rio de la Plata. Colección Lavradio I (1808-1809), 1961, p. 13.

15 Política lusitana en el Rio de la Plata. Colección Lavradio I (1808-1809), 1961, p. 13. [Grifo nosso]

${ }^{16}$ Política lusitana en el Rio de la Plata. Colección Lavradio I (1808-1809), 1961, p. 13.
} 
Lembramos que durante praticamente três séculos portugueses e espanhóis se digladiaram em solo americano, especialmente por territórios e por acusações mútuas de contrabando. Portanto, o governo português, ao enviar um ultimatum para os dirigentes de Buenos Aires, dava sinais de que acreditava que o Vice-Reinado do Rio da Prata, há pouco mais de trinta anos livre da dependência direta do vice-reinado do Peru, iria desligar-se tão facilmente de um sistema político e ideológico metropolitano espanhol relativamente bem arquitetado.

Diferentemente do que ocorria no Brasil, as colônias espanholas possuíam um sistema de ensino há muito tempo desenvolvido, a fim de inculcar nos criollos e indígenas o sentimento de pertencimento e de obediência ao rei. Assim, apesar das inúmeras diferenças étnicas e culturais existentes entre os povos que compunham o imenso império hispano-americano, a ligação com o rei e com as instituições espanholas sempre foram muito presentes.

Ressaltamos, então, mais dois pontos interessantes da correspondência enviada pelo ministro dom Rodrigo ao Cabildo de Buenos Aires: a relação com a Grã-Bretanha e a ameaça armada. Percebemos que, por vezes, o ministro português revela a estreita ligação de Portugal com os ingleses, afirmando, inicialmente, que não desejava "a un tiempo obrar con toda la fuerza de sus Armas y con la de sus Aliados", sendo que poderia "ebitar que qualesquiera nacion aliada pueda conserbar contra los mismos havitantes alguna memoria de lo pasado y pueda querer cometer contra ellos qualesquiera / acto de hostilidad ó de venganza" ${ }^{17}$, contando como certa a participação inglesa para a submissão do vicereinado ao trono português, ressaltando que contribuiriam para isso os ressentimentos de não terem conseguido manter a ocupação de Buenos Aires e Montevidéu nos anos anteriores.

$\mathrm{O}$ último excerto da correspondência referia-se à expulsão dos ingleses, em 1807, após a malfadada tentativa das forças britânicas em invadir Buenos Aires pela segunda vez. Mas, apesar dessas assertivas, no caso de haver uma decisão negativa por parte do Cabildo de Buenos Aires, resolvendo não se submeter ao poder e "proteção" do príncipe regente de Portugal, o aliado (leia-se, a Grã-Bretanha) seria demovido de integrar as forças que submeteriam pelas armas o Vice-Reinado do Rio da Prata, pois

${ }_{17}$ Política lusitana en el Rio de la Plata. Colección Lavradio I (1808-1809), 1961, p. 13-14. 
Su Alteza Real sera obligado à obrar en comunidad con su poderoso Aliado, y con los grandes y fuertes medios que la Probidencia deposito en Sus Reales manos, y tal bes a ver con dolor el glorioso y esperable suceso de sus armas, y a considerar con lastima que Pueblos unidos por los estrechos vinculos de la misma Sagrada Relijion, por las mismas costumbres y por el idioma que es casi el mismo, se buelban enemigos, y sacrifiquen sus mas Sagrados intereses ${ }^{18}$.

Sem perder tempo, em 15 de março de 1808 deu-se início ao que pode ser chamado de "missão Curado", em território platino. dom Rodrigo destacou o comandante Joaquim Xavier Curado para que fosse até o Rio da Prata, pois esperava que o agente português desse continuidade ao que havia proposto na missiva ao Cabildo ${ }^{19}$. Todavia, essa missão, que deveria ser rápida, acabou se arrastando por meses, levando a uma alteração crucial nos planos portugueses, tendo em vista não apenas o que Curado descreveria sobre a realidade no Prata, mas também as vicissitudes do cenário internacional.

Além disso, a troca de correspondências era um problema para se entabularem negociações em curto espaço de tempo, pois não se dispunha de nenhum meio de transporte eficaz na época, a não ser de cavalos ou de embarcações que iam até o Prata. Assim, os ofícios do ministro Sousa Coutinho enviados no final de março chegaram a Buenos Aires somente por volta da metade do mês de abril. Dessa forma, nas noites de 27 e 28 de abril de 1808, o Cabildo, após analisar as missivas portuguesas em reunião e deliberação, juntamente com o vice-rei interino Santiago de Liniers, resolveu sobre o que deveria ser observado para garantir a "lealtad con que este Cavildo se há conducido y conducirá siempre en obsequio de su legitimo y mui amado Soverano y Señor natural"20.

${ }_{18}$ Política lusitana en el Rio de la Plata. Colección Lavradio I (1808-1809), 1961, p. 14.

19 Conforme correspondência de Linhares a Curado, este último deveria "1 - he conseguir ser admitido em Monte Video e Buenos Ayres, e este ponto q. he o mais essencial, poderá vencelo per si, e por via do governador do Rio Grande, propondo a negociação de q. vai encarregado para segurar a continuação do Comercio, na forma, que se esta praticando [...] 2 - he tentar od governadores para o fim de unir aqueles paises ao Real Dominio, o que seria muito feliz, pois evitaria toda outra ulterior contenda. $\mathrm{O} 3$ he o exame e conhecimento verdadeiro do voto da Nação Hespanhola, e da Opinião Pública sobre entragarem-se ao Governo Português, e em qualquer cazo o conhecimento do estado da Força Pública em Soldado, Officiais, Munições, q. tem, e ocupa o Rio da Prata". apud Acevedo in: REVISTA do IHGB, jul./set. 1946, p. 175.

${ }^{20}$ Política lusitana en el Rio de la Plata. Colección Lavradio I (1808-1809), 1961, p. 16. 
Os representantes do governo do Vice-Reinado do Rio da Prata resolveram que seriam enviadas correspondências para a Espanha, informando sobre tudo que estava ocorrendo na América, especialmente em relação ao vice-reinado. Logo em seguida, dispuseram que deveriam ser imediatamente informados, de forma reservadíssima, o Vice-Reinado de Lima (Peru), as presidências do Chile, Cuzco e Charcas, assim como todas as intendências do interior, para que enviassem dinheiro, armamento e soldados para a defesa do Prata $^{21}$.

Essas primeiras medidas estavam de acordo com o que rezava a "cartilha" do Ancien Régime, tendo em vista que qualquer relação direta do vice-rei ou do cabildo com representantes de outro governo que interferisse nas relações internacionais ou em setores cruciais da administração implicava uma transgressão do Pacto Colonial. De acordo com as normas vigentes durante o absolutismo, não era permitido que representantes da burocracia colonial tomassem decisões sem o consentimento do rei ou de seus órgãos deliberativos metropolitanos.

No terceiro ponto a ser observado, o Cabildo comentava sobre dois ofícios enviados pelo brigadeiro Joaquim Xavier Curado e pelo tenente-general João da Silva Gama (na época governador da província de São Pedro), nos quais havia pontos discordantes no discurso acerca da relação que declaravam desejar manter entre o vice-reinado e a colônia portuguesa. Entretanto, julgavam que em alguns aspectos havia demonstrações dos mesmos intuitos da missiva do ministro Sousa Coutinho: a dominação pelas armas.

Assim, decidiram que Xavier Curado, que já se encontrava na qualidade de emissário do governo português em Montevidéu desde o mês de abril, desejando passar a Buenos Aires para discutir acordos com o vice-rei, deveria ficar detido na Banda Oriental. Essa prisão teria o intuito de que o "Governador de aquella Plaza [...] contestase à los puntos de su comision, y hecho se regresase desde alli a sus Territorios." 22 Entretanto, naquele momento, talvez na esperança de que o próprio Curado a motivasse, a ordem para aprisionar o comandante português não foi enviada por Liniers ao governador de Montevidéu.

Por fim, o Cabildo de Buenos Aires concluía que, pelo teor das correspondências recebidas e pelas intenções do ministro dom Rodrigo, a nação portuguesa e seu governo eram declaradamente seus inimigos. $\mathrm{Na}$ visão dos ouvidores, o motivo que havia levado os portugueses a

${ }^{21}$ Ibid.

${ }^{22}$ Política lusitana en el Rio de la Plata. Colección Lavradio I (1808-1809), 1961. p. 17. 
não terem promovido nenhuma invasão até aquele momento deviase ao fato de não possuírem o número necessário de tropas, pois, se as tivessem, fossem nacionais ou inglesas, já teriam realizado "las hostilidades, que no dejará de poner en exercício [...] resultando de aqui la inebitable perdida de toda la Campaña Oriental y ruina de sus habitantes y hacendados" 23 .

Assim, ficava decidido que o único meio possível para barrar o ataque lusitano seria a tomada de Rio Grande, por onde os portugueses teriam fácil acesso à Banda Oriental. Além disso, foi ratificado que a expedição platina não deveria se limitar somente ao Rio Grande:

sino también à la del Rio Pardo, y que para llamar à un tiempo y á puntos distantes entre si las atenciones de los Portugueses y ebitar su reunion expediria las correspondientes Ordenes para que al mismo (tiempo) se les atacase por la Provincia de Misiones y á sus establecimientos de Coimbra (Miranda) y Matogroso. ${ }^{24}$

Enquanto isso, em Montevidéu, Joaquim Xavier Curado seguia as ordens que havia recebido do ministro Sousa Coutinho e aguardava permissão para passar a Buenos Aires. Até o mês de setembro, ao menos, encarregou-se de observar os pontos que interessavam à Coroa portuguesa em relação ao vice-reinado, especialmente na Banda Oriental. Curado enviou um ofício reservado ao ministro dom Rodrigo de Sousa Coutinho, no qual fazia uma extensa e minuciosa descrição de todos os elementos que podiam ser importantes para levar adiante os planos portugueses em relação do Vice-Reinado do Rio da Prata. Nessa epístola, é possível verificar como estava caracterizada, na visão de Curado, a sociedade platina daquele período:

Os Estancieiros são os unicos, que acharião o seu interesse em hua união temporanea; porem como ao mesmo tempo são todos Comerciantes, e os beneficios que rezultão do Comercio são mais importantes, que o das Estancias, devem propender mais bem aos interesses daqueles, que d'estas. O interesse de todo o Povo portanto, he opposto á união ${ }^{25}$.

Ao examinar este excerto, verificamos o quanto Xavier Curado estava sendo específico em relação aos planos portugueses na região do

\footnotetext{
${ }^{23}$ Ibid.

${ }^{24}$ Política lusitana en el Rio de la Plata. Colección Lavradio I (1808-1809), 1961, p. 19.

${ }^{25}$ Arquivo Histórico do Itamaraty (AHI). Lata 193, maço 6, pasta 1.
} 
Rio da Prata. Portanto, demonstrava exatamente quais eram as intenções diplomáticas, políticas e militares de Portugal para a região. Além disso, fazia um minucioso relato de como estavam organizadas as principais nucleações populacionais da América Meridional.

A correspondência de Xavier Curado não é datada, mas podemos inferir, pelos comentários e dados que reproduziu, que deva ter sido escrita por volta de finais de abril de 1808, enquanto ele aguardava autorização do vice-rei Santiago de Liniers para passar a Buenos Aires e iniciar discussões sobre o plano de proteção do vice-reinado proposto pelo príncipe regente de Portugal. Assim relatava sobre a reação dos platinos ao receberem a notícia da vinda da família real portuguesa para a América:

Logo que os Hespanhoes tiverão noticia da vinda de S.A.R. para o Brazil, conceberão, que a da parte septentrional do Rio da Prata seria hua consequencia necessaria do estabelecimento deste novo Imperio. Se uniformavão em opinar, que não havia forças para rezistir aos Portuguezes; manifestavão hum grande e fundado receio de serem conquistados; porem nunca ouvi amais minima expreção, que podesse dar a entender que dezejavão unirse ao Brazil. ${ }^{26}$

Com isso, o comandante/espião do governo português declarava que não seria tão fácil a empresa que se pretendia no Prata, tendo em vista que a vontade do povo em unir-se a outra Coroa não tinha a mínima expressão. Entretanto, explicava que se podia tirar proveito da animosidade existente entre as duas principais cidades do Vice-Reinado do Rio da Prata, pois

Buenos Ayres considera Monte Video como húa Cidade Extrangeira cheia de traidores, e que offende aos moradores desta na honra, e nos interesses. Pode-se sacar hum grande partido desta antepatia, e agitar com expecialidade a plébe, que não poderia convencer-se por outros principios ${ }^{27}$.

A relação entre as duas cidades, desde a criação de Montevidéu, sempre estivera estremecida pela disputas econômicas e políticas, tendo em vista a proximidade entre as duas e, sobretudo, a concorrência mercantil pela principal via de ligação da América meridional com a Europa. Montevidéu tinha a primazia de estar mais bem situada para o

${ }^{26}$ AHI. Lata 193, maço 6, pasta 1.

27 AHI. Lata 193, maço 6, pasta 1. 
comércio marítimo da época, ao passo que Buenos Aires tinha melhor estrutura portuária e as principais casas de comércio que efetuavam a ligação comercial com a Espanha.

Curado, ao permanecer durante alguns meses em solo hispanoamericano notara as principais vicissitudes para que o plano da Coroa portuguesa em anexar o Vice-Reinado do Rio da Prata fosse posto em prática. Demonstrava, pelo que notamos inúmeras vezes nesta correspondência de quarenta e uma laudas, uma maior preocupação em evidenciar os detalhes da campanha da Banda Oriental do rio Uruguai, chamada por ele de "Banda Septentrional do Rio da Prata". Ao final da correspondência, Xavier Curado elencava os principais pontos pelos quais se podiam efetuar as ações do plano supracitado:

$1^{\circ}$ Precindir de toda a especie de inteligencias secretas esperando metelas em uso ao tempo em que se possão apoyar com a força, condição sem a qual me parece que nada se pode concluir.

$2^{\circ}$ Publicar hum Manifesto em que S.A.R. se mostre informado dos progressos que tem feito alguns principios revolucionarios, principal cauza da anarquia actual, e precursores das disgraças que amiação as Provincias do Rio da Prata. Principios que poem ao mesmo Senhor na necessidade de fazer ocupar pelo seu Exercito huma pozição que asegure a obediencia das Provincias ás antigas leys estabelecidas, [...] prometendo no entanto protecção favo[ável].

$3^{\circ}$ Fazer marchar ao mesmo tempo seis mil homens para occupar as cercanias de Monte Video em direitura.

Me atrevo a provar que estas forças são de sobejo para tomar Monte Video, e guardar todo o paiz comprehendido entre Maldonado, e Arroyo da China, até a Fronteira de Portugal. [...]

A Conquista de Buenos Ayres pode efectuarse com quinze mil homens em poucos dias, e sem derrame de sangues ${ }^{28}$.

Em relação ao primeiro item, Curado apresenta uma idéia que, por um lado, já estava sendo posta em prática pelo ministro Sousa Coutinho, tendo em vista que ele próprio, Joaquim Xavier Curado, era um dos enviados ao Prata, mesmo que em caráter não oficial, para que fornecesse as devidas informações sobre a situação política, econômica e militar do vice-reinado, assim como para dar início às propostas que o príncipe regente de Portugal faria aos governantes platinos.

Já, o último item exposto no trecho supracitado da carta de Xavier Curado, quando este afirmava que a dominação de Buenos

${ }^{28}$ AHI. Lata 193, maço 6, pasta 1. 
Aires poderia ser realizada sem derramamento de sangue, não há como deixar de imaginar que uma ação dessa grandeza - tendo em vista as correspondências que desde finais de 1808 estavam sendo enviadas aos diversos pontos da América Espanhola, pendindo auxílio para a proteção de Buenos Aires, além do retrospecto das invasões inglesas - pudesse resultar numa tomada pacífica da capital platina pelos portugueses.

\section{Considerações finais}

O desenrolar dos fatos, especialmente a partir do mês de agosto de 1808, faria com que se movimentasse uma verdadeira máquina de espionagem e ligações excusas entre o Rio de Janeiro e Buenos Aires, pela qual cada governo tentava adiantar-se aos acontecimentos, evitando ser pego desprevenido em caso de uma ação mais drástica do vizinho. A diplomacia, naquele período, parecia depender mais do serviço da espionagem "oficial" que da própria ação política dos representantes. Nenhum passo era dado sem antes dispor de informações, mesmo que não fossem seguras, das movimentações que ocorriam no lado que se pretendia convencer ou controlar. Neste caso, a região compreendida entre o Rio de Janeiro e Buenos Aires tornou-se palco para os mais diversos tipos de pessoas que desejavam o reconhecimento do monarca português, ou dos governantes platinos, para participar dos círculos de beneficiamento pessoal, nos quais poderiam desfrutar da possibilidade de absorção de parte do dinheiro circulante nesses meios.

Notamos, portanto, o quanto a conjunção dos fatores externos ao Vice-Reinado do Rio da Prata, como a invasão e desorganização de Espanha pelos franceses e a pressão inglesa sobre as possessões espanholas, e internos, como a falta de unidade entre os diversos setores do governo, podia levar os portugueses a crer que uma ação diplomática, ou militar, se fosse o caso, bem planejada, renderia ótimos frutos à Coroa bragantina com a desejada anexação do Vice-Reinado do Rio da Prata ao Império português.

\section{Referências}

AZEVEDO, Antonio Carlos do Amaral. Dicionário de nomes, termos e conceitos históricos. São Paulo: Nova Fronteira, 1990.

AZEVEDO, Francisca Nogueira de. Dom Joaquim Xavier Curado e a política Bragantina para as províncias platinas (1800-1808). Disponível em $<\mathrm{http}$ :/www.ifcs. ufrj.br/ ppghis/pdf/topoi5a6.pdf > . Acessado em: 31 de maio 2011, às 10:20h. 
FARIA, Sheila de Castro. A colônia Brasileira: economia e diversidade. São Paulo: Moderna, 2001.

FRAGOSO, João; BICALHO, Maria Fernanda; GOUVÊA, Maria de Fátima (Org.). $O$ Antigo Regime nos trópicos: a dinâmica imperial portuguesa (séculos XVI-XVIII). Rio de Janeiro: Civilização Brasileira, 2001. p. 319-338.

LAGO, Laurêncio. Brigadeiros e generais de dom João VI e dom Pedro I no Brasil. Dados biográficos, 1800-1831. Rio de Janeiro: Gráfica Laemmert, s.d.

LIMA, Oliveira. D. João VI no Brasil. São Paulo: Topbooks, 1996.

NORTON, Luís. A corte de Portugal no Brasil: notas, alguns documentos diplomáticos e cartas da imperatriz Leopoldina. 2. ed. São Paulo; Brasília: Ed. Nacional; INL, 1979.

ACEVEDO, Walter Alexandre. A missão secreta do marechal Curado ao Rio da Prata (1808-1808). In: REVISTA do IHGB, Rio de Janeiro, jul./set. 1946.

WILlIMAN, Jose Cláudio do Amaral; PONS, Carlos Panizza. La Banda Oriental em la lucha de los Impérios: 1503-1810. Montevidéu: Ediciones de la Banda Oriental, 1977. Tomo I. (Historia Uruguaya).

\section{Sites consultados}

$<$ http://cvc.cervantes.es/actcult/museo_naval/sala7/personajes/personajes_11.htm $>$. Acesso em: 31/05/2011, às $17 \mathrm{~h}$.

$<$ http://ar.geocities.com/genealogia_fernandez/pafg1139.htm\#32634>. Acesso em: $19 / 05 / 2011$, às $15: 30 h$.

\section{Documentação Consultada}

Arquivo Histórico do Itamaraty (AHI). Lata 193, maço 6, pasta 1.

Política lusitana en el Rio de la Plata. Colección Lavradio I (1808-1809). Buenos Aires: AGN, 1961. 